Jalan Teuku Umar, Lubuk Baja, Kota Batam-Indonesia Telp. 0778 - 4083113

Email : info@uis.ac.id / uibnusina@gmail.com Website : uis.ac.id

\title{
PENGARUH BUDAYA ORGANISASI DAN MOTIVASI TERHADAP KINERJA DENGAN KEPEMIMPINAN SEBAGAI INTERVENING PADA BINDA KEPRI
}

\author{
Agung Cahyo Putro ${ }^{1}$, Cahyo Budi Santoso ${ }^{2}$ Oktavianti $^{3}$ \\ ${ }^{1-3}$ Prodi Magister Manajemen, Program Pascasarjana, Universitas Riau Kepulauan, Indonesia \\ e-mail: agungcahyoputro14@gmail.com,cafana_07@gmail.com, vianti.310@yahoo.com
}

\begin{abstract}
This study aims to analyze the influence of organizational culture and motivation on performance in Binda Kepri. This research uses path analysis method and hypothesis testing and hypothesis testing using partial $t$ test and simultaneous $F$ test. The results showed (1) Organizational Culture had a positive and significant effect on the leadership of Binda Kepri (2) Motivation had a positive and significant effect on the leadership of Binda Kepri. (3) Organizational culture has a negative and insignificant effect on the performance of Binda Kepri (4) Motivation has a negative and insignificant effect on the performance of Binda Kepri. (5) Leadership has a positive and insignificant effect on Binda Kepri's performance (6) Organizational culture has a negative and insignificant effect on Binda Kepri's performance with leadership as mediation (7) Motivation has a negative and insignificant effect on Binda Kepri's performance with leadership as mediation.
\end{abstract}

Keywords: Organizational Culture, Motivation, Leadership, Performance.

\section{Pendahuluan}

Dalam rangka mewujudkan visi Badan Intelijen Negara (BIN), telah dirumuskan langkah-langkah strategis yang harus dilaksanakan secara bersama-sama oleh seluruh unsur yang ada dalam organisasi, dalam sebuah bentuk rumusan misi. Visi dan misi merupakan inti yang menjadi pedoman tertulis dalam sebuah sistem manajemen dengan menggambarkan tentang kondisi apa yang ingin dicapai, apa yang harus dilaksanakan, diutamakan dan diprioritaskan serta menjadi pangkal dari seluruh program atau kegiatan unit organisasi sebagai pelaksananya. Artinya pelaksanaan kegiatan di setiap lini dalam organisasi harus mengacu pada pedoman visi dan misi tersebut. Hal yang menjadi fokus dalam pencapaian pimpinan BIN tentu bagaimana agar misi dapat dilaksanakan dengan cepat, terukur dan dapat terpantau perkembangannya.

Sebagaimana yang telah ditetapkan dalam Rencana Strategis (Renstra) BIN, bahwa rumusan visi BIN di periode 2015-2019 yaitu "Terwujudnya Badan Intelijen Negara yang semakin profesional, objektif dan berintegritas guna mendukung sistem keamanan nasional dalam rangka mewujudkan Indonesia yang berdaulat, mandiri dan berkepribadian". Bersamaan dengan dirumuskannya visi tersebut, BIN juga telah menetapkan misi sebagai jawaban terkait apa saja yang harus dilakukan, artinya apabila seluruh misi dapat dilaksanakan dan dicapai dengan baik niscaya sebuah visi akan dapat terwujud dan tujuan strategis akan dirasakan manfaatnya secara luas.

Agar mudah dalam hal sosialisasi dan internalisasi kepada seluruh anggota organisasi, misi BIN diserukan dengan akronim "PROBIN" yang menjelaskan bahwa dalam melaksanakan tugas dan fungsinya, BIN harus lebih professional, objektif dan berintegritas 
sehingga menjadi sebuah karakter bagi setiap individu bagaimana bersikap dan bertindak dalam setiap keadaan/kondisi pelaksanaan tugas. Hal ini tentu akan terwujud jika seluruh unit organisasi di BIN telah matang dalam mengelola sebuah organisasi, memiliki mental yang mendukung organisasi berkinerja tinggi, penatalaksanaan yang jelas dan efektif, menjalankan pengelolaan SDM yang berbasis sistem merit, akuntabel, dan memiliki pengendalian intern yang dapat diandalkan. Guna dapat memberikan sebuah ukuran tentang sejauh mana pencapaian misi tersebut, Inspektorat Utama selaku quality assurance telah menginisiasi teknik dan metode pengukuran dan evaluasi, yang hasilnya memberikan gambaran yang meyakinkan dan dapat membantu pimpinan sebagai bahan pembuatan kebijakan terkait pelaksanaan visi dan misi yang telah dicanangkan. Pengukuran tersebut secara kuantitatif menghasilkan sebuah Indeks Kematangan Unit Organisasi (IKUO) yang substansinya telah diformalkan melalui Keputusan Kepala Badan Intelijen Negara Nomor: KEP-69/III/2019 tentang Pedoman Pengukuran dan Evaluasi Indeks Kematangan Unit Organisasi di Badan Intelijen Negara. IKUO adalah sebuah metode untuk mengukur dan mengevaluasi tingkat efektivitas dan efisiensi pelaksanaan tugas fungsi unit organisasi di BIN. Evaluasi ini bertujuan untuk mengetahui dan menganalisa sejauh mana efektivitas dari implementasi kegiatan dan sub kegiatan di unit organisasi dalam upaya mewujudkan visi BIN.

Salah satu masalah nasional yang dihadapi oleh Bangsa Indonesia saat ini adalah penanganan terhadap rendahnya kualitas Sumber Daya Manusia (SDM). Jumlah Sumber Daya Manusia yang besar apabila digunakan secara efektif dan efisien, hal ini akan bermanfaat untuk menunjang gerak lajunya pembangunan nasional yang berkelanjutan. Melimpahnya Sumber Daya Manusia yang ada saat ini mengharuskan berfikir secara seksama yaitu bagaimana dapat memanfaatkan Sumber Daya Manusia secara optimal. Agar di masyarakat memiliki Sumber Daya Manusia yang handal, maka diperlukan pendidikan yang berkualitas, penyediaan berbagai fasilitas sosial, lapangan pekerjaan yang memadai. Kelemahan dalam penyediaan berbagai fasilitas tersebut akan menyebabkan keresahan sosial yang akan berdampak kepada keamanan masyarakat. (Sinambela, 2019), (Suhardi; Ratih, Ida Aju Brahma; Sari, 2018) Saat ini kemampuan Sumber Daya Manusia masih rendah baik dilihat dari kemampuan intelektualnya maupun keterampilan teknis yang dimilikinya. Mengapa budaya organisasi penting, menurut Smircich, (2017), (Suhardi et al., 2018) karena merupakan kebiasaan-kebiasaan yang terjadi dalam hirarki organisasi yang mewakili normanorma perilaku yang diikuti oleh para anggota organisasi.

\section{Rumusan Masalah}

1) Apakah Budaya Organisasi berpengaruh terhadap Kepemimpinan?

2) Apakah Motivasi berpengaruh terhadap Kepemimpinan?

3) Apakah Budaya Organisasi berpengaruh terhadap Kinerja?

4) Apakah Motivasi berpengaruh terhadap Kinerja?

5) Apakah Kepemimpinan berpengaruh terhadap Kinerja?

6) Apakah Budaya Organisasi berpengaruh terhadap Kinerja dengan Kepemimpinan sebagai variabel intervening?

7) Apakah Motivasi berpengaruh terhadap Kinerja dengan Kepemimpinan sebagai variabel intervening?

\section{Tujuan Penelitian}

1) Untuk menganalisis pengaruh Budaya Organisasi terhadap Kepemimpinan.

2) Untuk menganalisis pengaruh Motivasi terhadap Kepemimpinan.

3) Untuk menganalisis pengaruh Budaya Organisasi terhadap Kinerja.

4) Untuk menganalisis pengaruh Motivasi terhadap Kinerja.

5) Untuk menganalisis pengaruh Kepemimpinan terhadap Kinerja. 
6) Untuk menganalisis pengaruh Budaya Organisasi terhadap Kinerja dengan Kepemimpinan sebagai variabel intervening.

7) Untuk menganalisis pengaruh Motivasi terhadap Kinerja dengan Kepemimpinan sebagai variabel intervening.

\section{Kajian Pustaka / Kajian teori Budaya Organisasi}

Kumar and Sharma (2018) menggambarkan organisasi sebagai entitas politik, di dalamnya terdapat berbagai kelompok atau koalisi yang tujuannya untuk melobi dan untuk mengarahkan perhatian organisasi terhadap kepentingan pribadi mereka sendiri dan tujuan tertentu. Menurut Tarifa et al (2019) lebih lanjut menyatakan bahwa konflik antar kelompok dapat timbul dari perbedaan mencapai tujuan atau perbedaan dalam persepsi realitas.

Adapun indikator budaya organisasi pada penelitian ini diambil menurut pandangan Mc Namara et al, (2018) yaitu: Budaya Organisasi Memiliki 1) Standarisasi, 2) Tujuan, 3) Nilai dan 4) Perilaku.

\section{Motivasi}

Motivasi kerja adalah suatu energi yang terdapat dalam diri seorang atau pegawai atau guru untuk mencapai tujuan organisasi. Sikap mental seseorang atau pegawai atau guru untuk mencapai tujuan organisasi. Sikap mental seseorang atau pegawai atau guru yang pro dan positif terhadap situasi kerja itulah yang dinamakan motivasi kerja yang akan melahirkan kinerja yang maksimal (Jabagi et al., 2019).

Adapun indikator motivasi pada penelitian ini diambil menurut pandangan McLeod (2018) dalam teori kebutuhan Maslow, yaitu: 1) Kebutuhan Fisiologi, 2) Kebutuhan Rasa Aman dan keselamatan, 4) Kebutuhan Sosial, 5) Kebutuhan Penghargaan, 6) Kebutuhan Aktualisasi Diri.

\section{Kopemimpinan}

Menurut Maheshwari dan Yadav, (2018) Kepemimpinan sebagai kemampuan untuk mempengaruhi suatu kelompok kearah tercapainya tujuan organisasi. Menurut Visone, (2018) kepemimpinan merupakan keseluruhan aktivitas dalam rangka mempengaruhi individu-individu agar mau dan berupaya untuk bekerjasama sesuai dengan wewenang dan tugasnya untuk mencapai tujuan yang diinginkan bersama dalam organisasi.

Berdasarkan uraian teori tentang defenisi kepemimpinan di atas, maka dapat disimpulkan bahwa kepemimpinan adalah suatu proses mempengaruhi orang ataupun komponen organisasi dengan memberikan motivasi-motivasi untuk saling bekerjasama dalam rangka mencapai tujuan bersama dalam organisasi.

Adapun indikator kepemimpinan pada penelitian ini diambil menurut pandangan Heritage et al., (2014), yaitu: 1) Kepemimpinan memiliki Kemampuan Personal, 2) Kemampuan Intelektual, 3) Kemampuan Keorganisasian

\section{Kinerja}

Kinerja adalah sesuatu yang dicapai atau prestasi yang diperlihatkan atau kemampuan bekerja, dengan kata lain kinerja dapat diartikan sebagai prestasi kerja. (Muange dan Maru, 2015; Liu et al., 2018).

Adapun indikator kinerja pada penelitian ini diambil menurut pandangan TarifaFernández et al., (2019), yaitu: 1) Quality of work, 2) Promptness, 3) Initiative, 4) Capability, 5) Communication. 


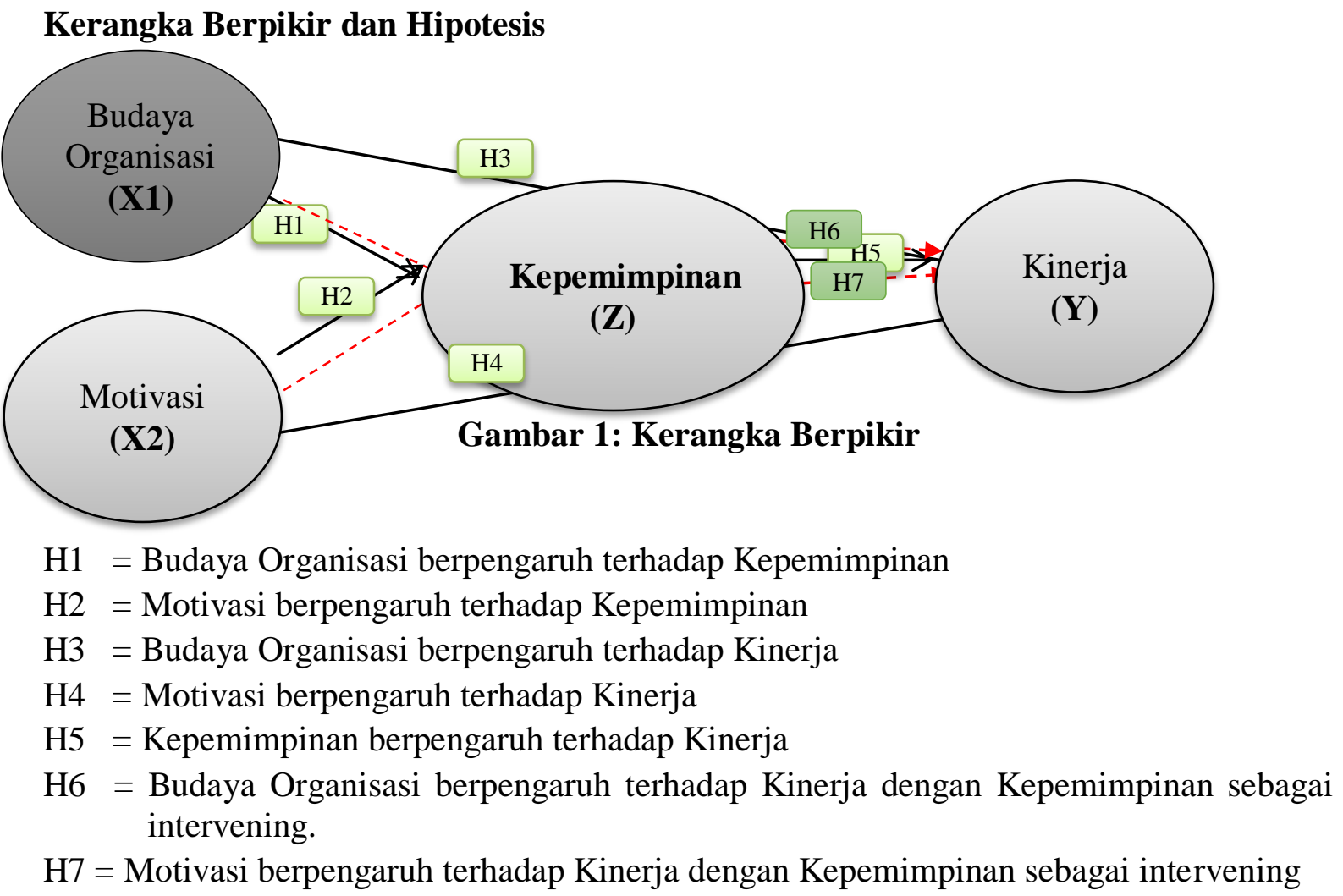

\section{Metode Penelitian}

\section{Populasi dan Sampel}

Populasi penelitian ini adalah seluruh pegawai Binda Provinsi Kepulauan Riau sebanyak 88 pegawai. Sumber pengumpulan data, pengumpulan data dapat dilakukan dengan kuisioner, observasi, wawancara dengan teknik purposive sampling, dengan kriteria yang dijadikan sebagai sampel penelitian adalah: 1) Sudah bekerja selama 1 tahun di BINDA Kepulauan Riau, 2) Memilik Nomor Induk Pegawai di BINDA Kepulauan Riau, 3) Memahami Visi dan Misi BINDA Kepulauan Riau, dengan jumlah sampel yang diambil adalah 74 responden.

Yang menjadi variabel independen dalam penelitian adalah: X1 = Budaya Organisasi, X2 $=$ Motivasi, dan variabel intervening $\mathrm{Z}=$ Kepemimpinan. Sedang yang menjadi variabel dependen dalam penelitian ini adalah: $\mathrm{Y}=$ Kinerja Pegawai

Penelitian ini dimulai dengan uji:

a. Uji Validitas

Untuk menguji validitas pada tiap-tiap item, dilakukan dengan mengkorelasikan skor tiap butir dengan skor total yang merupakan jumlah tiap skor butir. Koefisien korelasi yang dihasilkan kemudian dibandingakn dengan standar validitas yang berlaku. Syarat sudah terpenuhi karena $r \geq 0,30$ maka pertanyaan dari kuisioner adalah valid

b. Uji Reliabilitas

Pengujian reliabilitas dapat mengacu pada nilai Cronbach Aplha $(\alpha)$, dimana suatu konstruk atau variabel dinyatakan reliabel apabila memiliki Cronbach Apha $(\alpha)>0.7$ yang menyatakan bahwa penelitian ini adalah reliabel. 
Uji Asusmsi Klasik

Layak atau tidak model regresi pada uji asumsi klasik untuk memprediksi variabel terikat berdasarkan masukan variabel dipenden, maka model regresi wajib tidak ditemukan dari beberapa asumsi yaitu:

c. Uji Normalitas

Penelitian ini memiliki data berdistribusi normal.

d. Uji Multikolinearitas.

Variabel-variabel tidak orthogonal jika saling berkorelasinya variabel independen, dan tidak terjadi terjadi korelasi diantara variabel independen, dengan nilai tolerance > 0.10 , atau sama dengan nilai $\mathrm{VIF}<10$, maka dapat dikatakan bahwa model regresi tidak terdapat gejala multikolinearitas.

e. Uji Heteroskedastisitas

Bertujuan menguji dalam regresi terjadi ketidaksamaan variance dari residual satu pengamatan ke pengamatan yang lain. Regresi yang homoskedastisitas atau tidak terjadi heteroskedastisitas.

f. Pengujian Hipotesis

Analisis Regresi Linier Berganda

Mendapatkan pengaruh atau tidaknya antara variabel independen dengan variabel dependen.

g. Uji T (Parsial)

Dengan ketentuan $t_{\text {hitung }}>t_{\text {tabel }}$ atau probabilitas kesalahan dibawah 5\% maka Ha diterima dan Ho ditolak pembuktian secara parsial variabel tidak bebas dipengaruhi variabel bebas secara. Mendapatkan pengaruh antara variabel bebas dan terikat adalah tujuan regresi liner berganda.

h. $\quad \mathrm{Uji} \mathrm{R}^{2}$

Nilai Koefisien antara 0 dan 1 variabel-variabel independen menjelaskan variasi variabel dependen adalah tujuan uji $\mathrm{R}^{2}$ dalam regresi linier berganda.

\section{Hasil dan Pembahasan}

Karakteristik Responden

Karakteristik responden pada penelitian ini dapat dilihat pada tabel berikut:

Tabel 1: Responden Berdasarkan Jenis Kelamin

\begin{tabular}{lcc}
\hline Keterangan & Jumlah Responden & Persentase \\
\hline Laki -laki & 57 & $77,03 \%$ \\
\hline Perempuan & 17 & $22,97 \%$ \\
\hline Jumlah & 74 & $100 \%$ \\
\hline
\end{tabular}

Tabel 2: Responden Berdasarkan Usia

\begin{tabular}{lcc}
\hline \multicolumn{1}{c}{ Keterangan } & Jumlah Responden & Persentase \\
\hline $21-30$ tahun & 65 & $87,80 \%$ \\
\hline $31-40$ tahun & 4 & $05,40 \%$ \\
\hline $41-50$ tahun & 3 & $04.10 \%$ \\
\hline $51-60$ tahun & 2 & $02.70 \%$ \\
\hline Jumlah & 74 & $100 \%$ \\
\hline
\end{tabular}


Tabel 3: Responden Berdasarkan Pendidikan

\begin{tabular}{lcc}
\hline Keterangan & Jumlah Responden & Persentase \\
\hline SMA/SMK & 21 & $28.4 \%$ \\
\hline Diploma & 18 & $24.3 \%$ \\
\hline Sarjana (S1) & 43 & $58.1 \%$ \\
\hline Magister (S2) & 2 & $02.7 \%$ \\
\hline Doktor (S3) & 2 & $02.7 \%$ \\
\hline Jumlah & 74 & $100 \%$ \\
\hline
\end{tabular}

Tabel 4: Responden Berdasarkan Jabatan

\begin{tabular}{lcc}
\hline \multicolumn{1}{c}{ Keterangan } & Jumlah Responden & Persentase \\
\hline Kasie & 2 & $02.7 \%$ \\
\hline Kasubag & 2 & $02.7 \%$ \\
\hline Fungsional & 47 & $63.5 \%$ \\
\hline Pelaksana & 23 & $31.1 \%$ \\
\hline lainnya & 0 & 0 \\
\hline Jumlah & 74 & $100 \%$ \\
\hline
\end{tabular}

Tabel 5: Responden Berdasarkan Masa Jabatan

\begin{tabular}{lcc}
\hline \multicolumn{1}{c}{ Keterangan } & Jumlah Responden & Persentase \\
\hline$<1$ tahun & 0 & 0 \\
\hline$>1-3$ tahun & 70 & $94.6 \%$ \\
\hline$>3-5$ tahun & 2 & $02.7 \%$ \\
\hline$>5-10$ tahun & 2 & $02.7 \%$ \\
\hline Jumlah & 74 & $100 \%$ \\
\hline
\end{tabular}

Sumber: Data diolah SPSS, 2020

Tabel 6: Deskriptif Statistik

\begin{tabular}{lccccr}
\hline \multicolumn{7}{c}{ Descriptive Statistics } \\
& $\mathrm{N}$ & $\begin{array}{c}\text { Minim } \\
\text { um }\end{array}$ & $\begin{array}{c}\text { Maxi } \\
\text { mum }\end{array}$ & Mean & $\begin{array}{c}\text { Std. } \\
\text { Deviation }\end{array}$ \\
\hline $\begin{array}{l}\text { Rata2_Budaya_Organisasi } \\
\text { (X1) }\end{array}$ & 74 & 2.00 & 5.00 & 3.9459 & .70013 \\
\hline Rata2_Motivasi (X2) & 74 & 3.00 & 4.00 & 3.9257 & .25752 \\
\hline Rata2_Kepemimpinan (Z) & 74 & 2.00 & 5.00 & 3.9730 & .68192 \\
\hline Rata2_Kinerja (Y) & 74 & 2.00 & 5.00 & 3.9392 & .60790 \\
\hline Valid N (listwise) & 74 & & & & \\
\hline
\end{tabular}

Sumber: Data diolah SPSS, 2020 


\section{Hasil dan Pembahasan}

\section{Uji Normalitas}

Tabel 7: Uji One - Sample Kolmogorov - Smirnove Test One-Sample KolmogorovSmirnov Test

\begin{tabular}{llr}
\hline & & Unstandardized Residual \\
\hline $\mathrm{N}$ & & 74 \\
\hline Normal Parameters ${ }^{\mathrm{a}, \mathrm{b}}$ & Mean & .0000000 \\
\cline { 2 - 3 } & Std. & 3.41009847 \\
& Deviation & .128 \\
\hline \multirow{2}{*}{$\begin{array}{l}\text { Most Extreme } \\
\text { Differences }\end{array}$} & Absolute & .071 \\
\cline { 2 - 3 } & Positive & -.128 \\
\cline { 2 - 3 } & Negative & .128 \\
\hline Test Statistic & & $.204^{\mathrm{c}}$ \\
\hline Asymp. Sig. (2-tailed) & \\
\hline a. Test distribution is Normal. & \\
\hline \multicolumn{2}{l}{ b. Calculated from data. } & \\
\hline \multicolumn{2}{c}{ c. Lilliefors Significance Correction. } \\
\hline
\end{tabular}

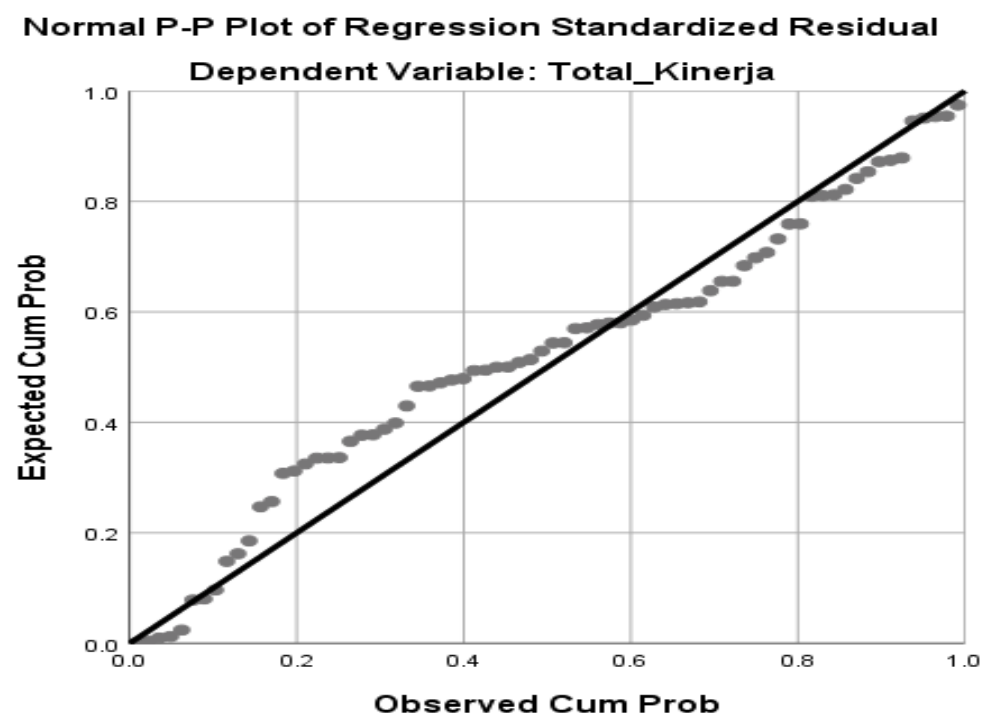

Gambar 2: Grafik Normal P-P Plot Of Regression Standardized Residual

\section{Hasil Uji Multikolinieritas}

Tabel 8: Hasil Nilai Uji Multikolinearitas

\begin{tabular}{lcc}
\hline \multirow{2}{*}{\multicolumn{1}{c}{ Variabel }} & \multicolumn{2}{c}{ Collinearity Statistics } \\
\cline { 2 - 3 } & Tolerance & VIF \\
\hline Budaya Organisasi (X1) & .974 & 1.027 \\
\hline Motivasi (X2) & .688 & 1.453 \\
\hline Kepemimpinan (Z) & .673 & 1.488 \\
\hline
\end{tabular}

Sumber: Data diolah SPSS, 2020 


\section{Uji Heteroskedastisitas}

\section{Dependent Variable: Kinerja}

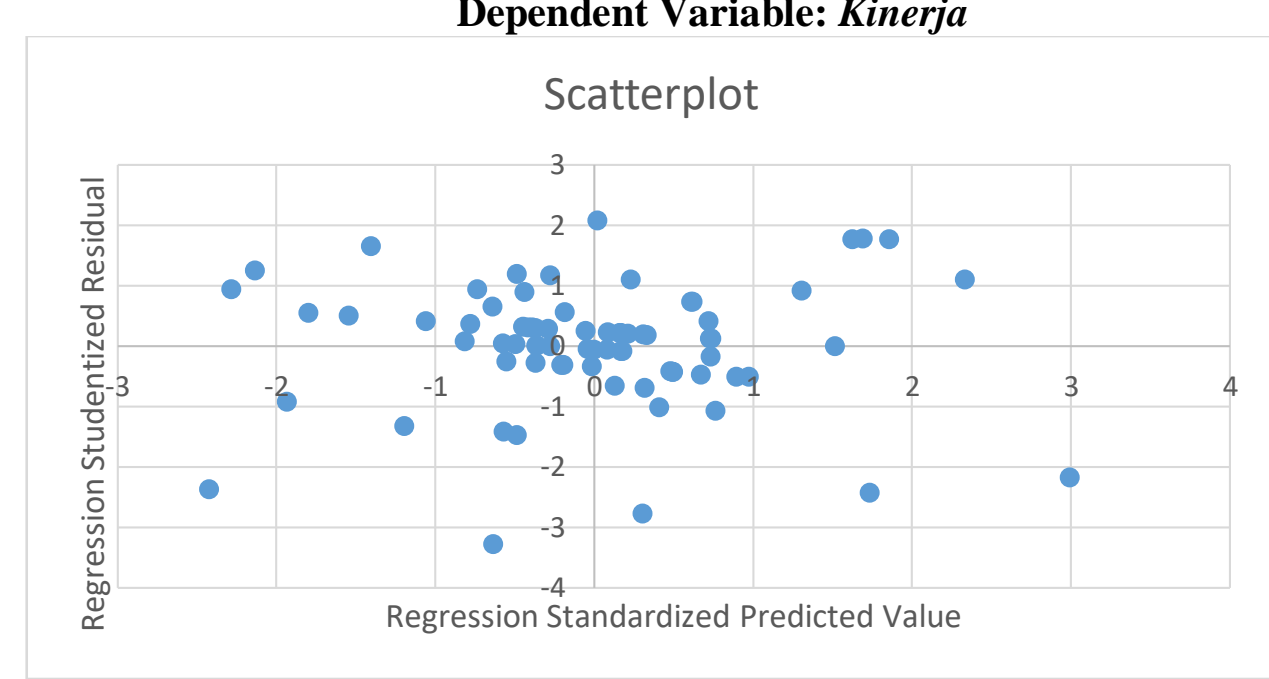

Gambar 3: Grafik Scatterplot

Sumber: Data diolah SPSS, 2020

Hasil Uji Regresi Linier Berganda

Tabel 9: Hasil Analisis Regresi Linier Berganda

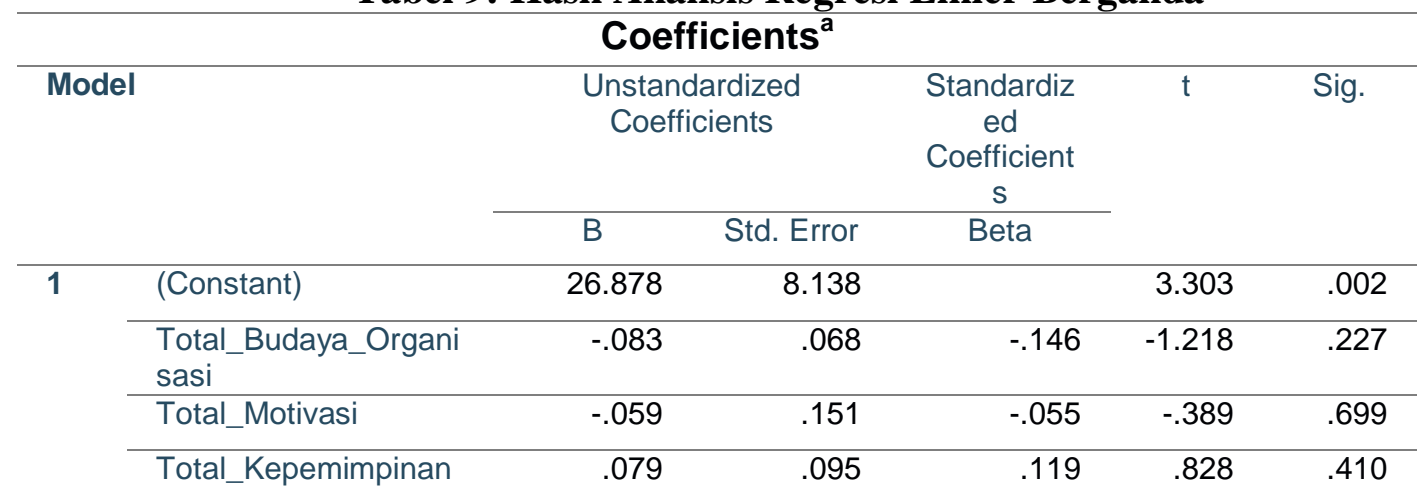

a. Dependent Variable: Total_Kinerja

Berdasarkan hasil ouput SPSS v25 yang didapat, diperoleh persamaan:

$Y^{\prime}=26,878-0,083 X 1-0,059$ X2 + 0,079Z + e

Penjelasan dari persamaan tersebut adalah sebagai berikut:

1) Konstanta dengan nilai 26.878 artinya jika variabel budaya organisasi, motivasi, kepemimpinan maka kinerja pegawai adalah 26,878.

2) Koefisien regresi variabel budaya organisasi sebesar -0.083 artinya jika variabel independen lain dianggap nol dan nilai budaya organisasi mengalami peningkatan $1 \%$, maka kinerja pegawai akan mengalami penurunan nilai sebesar -0.083

3) Koefisien regresi variabel motivasi sebesar -0.059 artinya jika variabel independen lain dianggap nol dan motivasi mengalami peningkatan $1 \%$, maka kinerja pegawai akan mengalami penurunan nilai sebesar $-0,059$.

4) Koefisien regresi variabel kepemimpinan sebesar 0,079 artinya jika variabel dependen dianggap nol dan nilai kepemimpinan mengalami peningkatan $1 \%$, maka kinerja pegawai akan mengalami kenaikan nilai sebanyak 0,079 . 


\section{Hasil Uji Hipotesis}

Uji t (Parsial)

Tabel 10: Uji Hipotesis dengan Uji t

\begin{tabular}{|c|c|c|c|c|c|c|}
\hline \multicolumn{7}{|c|}{ Coefficients $^{a}$} \\
\hline \multirow{2}{*}{\multicolumn{2}{|c|}{ Model }} & \multicolumn{2}{|c|}{$\begin{array}{l}\text { Unstandardized } \\
\text { Coefficients }\end{array}$} & \multirow{2}{*}{$\begin{array}{c}\text { Standardiz } \\
\text { ed } \\
\text { Coefficient } \\
\text { s } \\
\text { Beta }\end{array}$} & \multirow[t]{2}{*}{$\mathrm{t}$} & \multirow[t]{2}{*}{ Sig. } \\
\hline & & B & Std. Error & & & \\
\hline \multirow[t]{4}{*}{1} & (Constant) & 26.878 & 8.138 & & 3.303 & .002 \\
\hline & $\begin{array}{l}\text { Total_Budaya_Organisa } \\
\text { si }\end{array}$ & -.083 & .068 & -.146 & -1.218 & .227 \\
\hline & Total_Motivasi & -.059 & .151 & -.055 & -.389 & .699 \\
\hline & Total_Kepemimpinan & .079 & .095 & .119 & .828 & .410 \\
\hline
\end{tabular}

a. Dependent Variable: Total_Kinerja

Sumber: Data diolah SPSS Versi 25, 2020

Dari hasil uji t dapat dideskripsikan sebagai berikut:

1) Variabel budaya organisasi berpengaruh tidak signifikan terhadap variabel dependen kinerja

2) Variabel motivasi berpengaruh tidak signifikan terhadap variabel dependen kinerja.

3) Variabel kepemimpinan berpengaruh tidak signifikan terhadap variabel dependen kinerja

\section{Uji Adjusted R Square}

Tabel 11: Hasil Nilai Adjusted R Square Model Summary

\begin{tabular}{lcccr}
$\begin{array}{l}\text { Mode } \\
\text { I }\end{array}$ & R & R Square & $\begin{array}{c}\text { Adjusted R } \\
\text { Square }\end{array}$ & $\begin{array}{r}\text { Std. Error of } \\
\text { the Estimate }\end{array}$ \\
\hline 1 & $.163^{\mathrm{a}}$ & .326 & .615 & 3.482 \\
\hline $\begin{array}{l}\text { a. Predictors: } \\
\text { Total_Budaya_Organisasi, Total_Motivasi }\end{array}$ & (Constant), & Total_Kepemimpinan, \\
\hline b. Dependent Variable: Total_Kinerja
\end{tabular}

Sumber: Data diolah SPSS Versi 25, 2020

Tabel hasil Nilai Adjusted R Square menunjukkan bahwa bahwa variabel independen yaitu gaya budaya organisasi, motivasi dan kepemimpinan secara bersama-sama memberikan pengaruh sebesar $61,5 \%$ terhadap variabel dependen kinerja.

\section{Hasil Uji Path Analisis}

a. Persamaan Jalur Model 1

Tabel 12. Hasil Coefficients Regresi Model 1

\begin{tabular}{|c|c|c|c|c|c|c|}
\hline \multicolumn{7}{|c|}{ Coefficients $^{a}$} \\
\hline \multirow{2}{*}{\multicolumn{2}{|c|}{ Model }} & \multicolumn{2}{|c|}{$\begin{array}{l}\text { Unstandardized } \\
\text { Coefficients }\end{array}$} & \multirow{2}{*}{$\begin{array}{c}\text { Standardized } \\
\text { Coefficients } \\
\text { Beta }\end{array}$} & \multirow[t]{2}{*}{$\mathrm{t}$} & \multirow[t]{2}{*}{ Sig. } \\
\hline & & B & $\begin{array}{l}\text { Std. } \\
\text { Error }\end{array}$ & & & \\
\hline & (Constant) & 1,312 & 2,058 & & ,763 & ,216 \\
\hline & $\begin{array}{l}\text { Budaya_Organisasi } \\
\text { (X1) }\end{array}$ & ,351 & ,071 & ,341 & 3,713 & ,000 \\
\hline
\end{tabular}




\begin{tabular}{lllll}
\hline Motivasi (X2) , 333 & , 100 & ,31 & 3,061 &, 000 \\
\hline a. Dependent Variable: Kepemimpinan (Z) & & & &
\end{tabular}

Berdasarkan tabel 12, dapat diketahui bahwa nilai sig Budaya Organisasi $(\mathrm{X} 1)=0.000$, Motivasi $(X 2)=0.00$ lebih kecil dari 0,05. Hasil ini memberikan kesimpulan bahwa model regresi 1, yakni variabel X1 dan X2 berpengaruh signifikan terhadap Kepemimpinan (Z).

b. Persamaan Jalur Model 2

Tabel 13. Hasil Coeficiients Regresi Model 2

\begin{tabular}{|c|c|c|c|c|c|c|}
\hline \multicolumn{7}{|c|}{ Coefficients $^{a}$} \\
\hline \multirow{2}{*}{\multicolumn{2}{|c|}{ Model }} & \multicolumn{2}{|c|}{$\begin{array}{l}\text { Unstandardized } \\
\text { Coefficients }\end{array}$} & \multirow{2}{*}{$\begin{array}{c}\text { Standardiz } \\
\text { ed } \\
\text { Coefficient } \\
\text { s } \\
\text { Beta }\end{array}$} & \multirow[t]{2}{*}{$\mathrm{t}$} & \multirow[t]{2}{*}{ Sig. } \\
\hline & & B & Std. Error & & & \\
\hline \multirow[t]{4}{*}{1} & (Constant) & 26.878 & 8.138 & & 3.303 & .002 \\
\hline & $\begin{array}{l}\text { Total_Budaya_Organi } \\
\text { sasi }\end{array}$ & -.083 & .068 & -.146 & -1.218 & .227 \\
\hline & Total_Motivasi & -.059 & .151 & -.055 & -.389 & .699 \\
\hline & Total_Kepemimpinan & .079 & .095 & .119 & .828 & .410 \\
\hline
\end{tabular}

a. Dependent Variable: Total_Kinerja

Berdasarkan Tabel 13, dapat diketahui bahwa nilai sig Budaya Organisasi $(\mathrm{X} 1)=$ 0.227 , Motivasi $(X 2)=0.699$ dan Kepemimpinan $(Z)=0.410$ lebih besar dari 0,05. Hasil ini memberikan kesimpulan bahwa model regresi 2, yakni variabel Budaya Organisasi (X1), Motivasi (X2) dan Kepemimpinan (Z) berpengaruh tidak signifikan terhadap Kinerja $(\mathrm{Y})$.

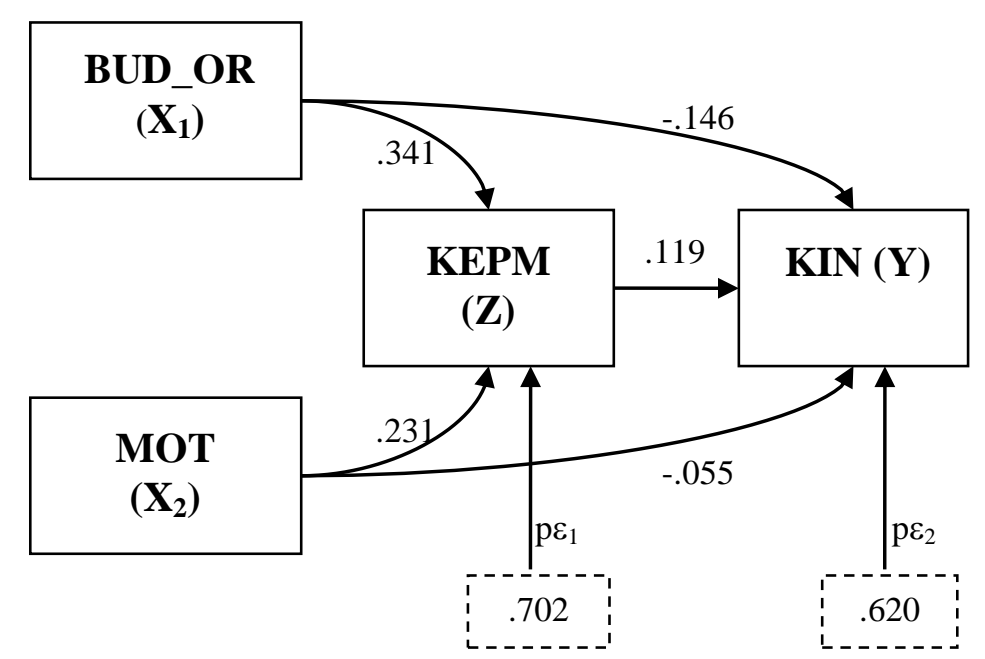

\section{Pembahasan}

Gambar. 4: Model Analisis Jalur (Part Analysis)

1) Pengaruh Budaya Organisasi terhadap Kepemimpinan

Variabel budaya organisasi berpengaruh positif dan signifikan terhadap kinerja pegawai di Binda Kepri. Hal ini disebabkan kepemimpinan mampu menyesuaikan dengan budaya organisasi. Kesimpulannya adalah semakin baik budaya organisasi maka dapat meningkatkan kepemimpinan di Binda Kepri. Hasil penelitian ini mengkonfirmasi penelitian yang dilakukan oleh Kumar dan Sharma (2018) yang menyatakan terdapat pengaruh signifikan antara Budaya Organisasi terhadap Kepemimpinan 
2) Pengaruh Motivasi terhadap Kepemimpinan

Variabel motivasi berpengaruh positif dan signifikan terhadap kepemimpinan di Binda Kepri. Hal ini disebabkan kepimpinan mampu memotivasi pegawai dengan baik di Binda Kepri Kesimpulannya adalah semakin baik motivasi maka akan dapat meningkatkan kepemimpian di Binda Kepri menjadi lebih baik. Hasil penelitian ini mengkonfirmasi penelitian yang dilakukan oleh Ridzuan Masri et al., (2018) Motivasi dapat disimpulkan sebagai suatu perubahan energi dalam diri seseorang yang ditandai dengan munculnya perasaan dan didahului dengan adanya tujuan, dan mengkonfirmasi penelitian Maheshwari dan Yadav, (2018) Kepemimpinan sebagai kemampuan untuk mempengaruhi suatu kelompok kearah tercapainya tujuan organisasi.

3) Pengaruh Budaya Organisasi terhadap Kinerja

Variabel budaya organisasi berpengaruh negatif dan tidak signifikan terhadap kinerja pegawai di Binda Kepri. Hal ini menandakan bahwa hubungan budaya organisasi dengan kinerja pegawai adalah berbanding terbalik, dan pengaruhnya tidak signifikan terhadap kinerja pegawai. Ini berarti bahwa adanya budaya organisasi maupun tidak adanya budaya organisasi di Binda Kepri, kinerja pegawai tetap saja baik.

Hasil penelitian ini tidak mengkonfirmasi penelitian yang dilakukan oleh Fajarini 2014; Csaszar 2016; Muthumari et al. 2018) Budaya organisasi merupakan ciri khas suatu organisasi dalam upaya mencapai tujuan yang telah ditetapkan oleh masingmasing organisasi. Pola-pola dari kepercayaan, simbol, ritual dan mitos yang berkembang dari waktu ke waktu berfungsi sebagai perekat yang menyatukan organisasi. Dan juga tidak mengkonfirmasi penelitian yang dilakukan oleh Kumar and Sharma 2018), bahwa Budaya organisasi adalah semua ciri yang menunjukkan kebiasaan suatu organisasi, keyakinan bersama, nilai-nilai dan perilaku-perilaku yang dianut oleh semua anggota organisasi. Budaya organisasi merupakan tradisi yang sangat sukar diubah.

4) Pengaruh Motivasi terhadap Kinerja

Variabel motivasi berpengaruh negatif dan tidak signifikan terhadap kinerja pegawai di Binda Kepri. Hal ini menandakan bahwa hubungan motivasi dengan kinerja pegawai adalah berbanding terbalik, dan pengaruhnya tidak signifikan terhadap kinerja pegawai. Ini berarti bahwa adanya motivasi maupun tidak adanya motivasi di Binda Kepri, kinerja pegawai tetap saja baik. Hasil penelitian ini tidak mengkonfirmasi penelitian yang dilakukan oleh Ridzuan Masri et al., (2018), Motivasi kerja adalah suatu energi yang terdapat dalam diri seorang atau pegawai atau guru untuk mencapai tujuan organisasi. Sikap mental seseorang atau pegawai pro dan positif terhadap situasi kerja itulah yang dinamakan motivasi kerja yang akan melahirkan kinerja yang maksimal.

5) Pengaruh Kepemimpinan terhadap Kinerja

Variabel kepemimpinan berpengaruh positif dan tidak signifikan terhadap kinerja pegawai di Binda Kepri. Hal ini menandakan bahwa hubungan motivasi dengan kinerja pegawai adalah berbanding lurus namun pengaruhnya tidak signifikan terhadap kinerja pegawai. Ini berarti bahwa adanya kepemimpinan maupun tidak adanya kepemimpinan di Binda Kepri, kinerja pegawai tetap saja baik. Hasil penelitian ini tidak mengkonfirmasi penelitian yang dilakukan oleh Maheshwari et al, (2019) dan penelitian yang dilakukan oleh (Berson et al., 2018) Kepemimpinan adalah usaha sadar yang dilakukan pimpinan untuk mempengaruhi anggotanya melaksanakan tugas sesuai dengan harapannya, dan suatu proses mempengaruhi orang lain untuk mencapai pengembangan atau tujuan oragnisasi”. 
6) Pengaruh Budaya Organisasi terhadap Kinerja dengan Kepemimpinan sebagai intervening

Variabel Budaya Organisasi melalui Kepemimpinan berpengaruh negatif dan tidak signifikan terhadap kinerja pegawai di Binda Kepri. Hasil penelitian ini tidak mengkonfirmasi penelitian yang dilakukan oleh Rokib dan Santoso, (2018). Budaya organisasi sebagai sistem nilai yang diyakini oleh semua anggota organisasi, yang dipelajari, diterapkan dan dikembangkan secara berkesinambungan, berfungsi sebagai sistem perekat, dan dapat dijadikan acuan berperilaku dalam organisasi untuk mencapai tujuan organisasi yang telah ditetapkan.

7) Pengaruh Motivasi Terhadap Kinerja dengan Kepemimpinan sebagai Intervening Variabel Motivasi melalui Kepemimpinan berpengaruh negatif dan tidak signifikan terhadap kinerja pegawai di Binda Kepri. Hasil penelitian ini tidak mengkonfirmasi penelitian yang dilakukan oleh Zhu et al., (2019) dan juga Visone, (2018) Kepemimpinan sebagai upaya ataupun usaha menggunakan gaya yang dimiliki dengan mempengaruhi tetapi tidak memaksa untuk memotivasi individu maupun organisasi dalam mencapai tujuan tertentu.

\section{Simpulan}

Berdasarkan hasil penelitian dapat diambil kesimpulan sebagai berikut:

1. Budaya organisasi terhadap Kepemimpinan berpengaruh positif dan signifikan.

2. Motivasi terhadap Kepemimpinan berpengaruh positif dan signifikan.

3. Budaya organisasi terhadap Kinerja berpengaruh negatif dan tidak signifikan.

4. Motivasi terhadap kinerja berpengaruh negatif dan tidak signifikan.

5. Kepemimpinan terhadap Kinerja berpengaruh positif dan tidak signifikan.

6. Budaya Organisasi melalui Kepemimpinan sebagai intervening berpengaruh negatif dan tidak signifikan terhadap kinerja pegawai di Binda Kepri.

7. Motivasi melalui Kepemimpinan sebagai intervening berpengaruh negatif dan tidak signifikan terhadap kinerja pegawai di Binda Kepri..

\section{Daftar Pustaka}

Berson, Y., Kark, R., Eilam-Shamir, G., \& Katz, I. (2018). Leadership now: Reflecting on the legacy of Boas Shamir. Monographs in Leadership and Management, 9, 315-323. https://doi.org/10.1108/S1479-357120180000009008

Csaszar, F. A. (2016). Organizational structure as a determinant of performance: Evidence from mutual funds. In Strategic Management Journal. https://doi.org/10.1002/smj.1969

Fajarini, U. (2014). PERANAN KEARIFAN LOKAL DALAM PENDIDIKAN KARAKTER. SOSIO DIDAKTIKA: Social Science Education Journal. https://doi.org/10.15408/sd.v1i2.1225

Heritage, O., Wealth, G., Limited, M., Limited, S., Achievements, O., Analysis, C. S., C, O. T., Victoria, O., Wang, F., Chich-jen, S., Mei-ling, T., Tan, M., Hee, T. F., Piaw, C. Y., Change, O., Study, C., Nanjundeswaras, T. S., Swamy, D. R., Spinks, N., ... Horner, M. (2014). MANUAL for the LEADER BEHAVIOR DESCRIPTION QUESTIONNAIRE - Form XII An Experimental Revision. Leadership Quarterly. https://doi.org/10.1017/CBO9781107415324.004

Janawi, J. (2019). The Conversion of the Lom belief through the Transformation of Islamic Religious Education in the Mapur Tribal of Bangka District. Bangka Belitung Islands Province, Indonesia. https://doi.org/10.4108/eai.10-9-2019.2289326

Kumar, N., \& Sharma, D. D. (2018a). How strategic knowledge management drives 
intellectual capital to superior innovation and market performance. International Marketing Review, 35(5), 806-832. https://doi.org/10.1108/IMR-09-2014-0299

Maheshwari, S. K., \& Yadav, J. (2019). The role of HR in leadership development. Development and Learning in Organizations, 33(5), 20-23. https://doi.org/10.1108/DLO-11-2018-0141

McLeod, S. (2018). Maslow' s Hierarchy of Needs Maslow's Hierarchy of Needs. Business.

Muange, R., \& Maru, L. C. (2015). Strategic alliances on performance of retail firms in Nairobi county, Kenya. TQM Journal, 27(6), 732-740. https://doi.org/10.1108/TQM-062015-0075

Ridzuan Masri, Arman Ahmad, \& Razlina Abd Rani. (2018). Teori maslow dalam konteks memenuhi keperluan asas pekerja dan peranannya dalam meningkatkan prestasi organisasi: kajian dan perspektif islam. Jurnal Hadhari.

Rokib, M. N., \& Santoso, D. (2018). Pengaruh Gaya Kepemimpinan Partisipatif Dan Komunikasi Organisasi Terhadap Kinerja Karyawan Melalui Kepuasan Kerja Sebagai Variabel Intervening. Jurnal Riset Ekonomi Dan Bisnis. https://doi.org/10.26623/jreb.v11i2.1080

Suhardi; Ratih, Ida Aju Brahma; Sari, I. A. B. (2018). The Effect Of Competence , Compensation Of Organizational Citizenship Behavior And Performance Of Employees In Life Insurance Companies In Batam City. Archives of Business Research, 6(10), 295307.

Suhardi, Banjarnahor, H., Adam, S., \& Kurniawan, A. D. E. (2018). The role of information technology in knowledge management in small medium enterprise. Journal of Theoretical and Applied Information Technology. http://www.scopus.com/inward/record.url?eid=2-s2.085059478343\&partnerID=MN8TOARS

Tarifa-Fernández, J., de-Burgos-Jimenez, J., \& Cespedes-Lorente, J. (2019). Absorptive capacity as a confounder of the process of supply chain integration. Business Process Management Journal, 25(7), 1587-1611. https://doi.org/10.1108/BPMJ-12-2017-0340

Visone, J. D. (2018). Empowerment through a teacher leadership academy. Journal of Research in Innovative Teaching \& Learning, 11(2), 192-206. https://doi.org/10.1108/jrit-08-2018-0019

Zhou, C., Hu, N., Wu, J., \& Gu, J. (2018). A new scale to measure cross-organizational cultural intelligence: Initial development and validation. Chinese Management Studies, 12(3), 658-679. https://doi.org/10.1108/CMS-10-2017-0309 